\title{
Days of "Zero" level geomagnetic activity accompanied by the high neutron activity and dynamics of some medical events-Antipodes to geomagnetic storms
}

\author{
E. Stoupel ${ }^{1,2}$, E. S. Babayev ${ }^{3}$, E. Abramson ${ }^{4}$, J. Sulkes ${ }^{4}$

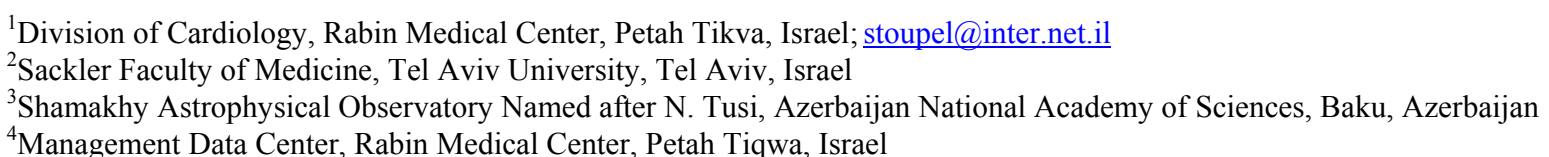 \\ ${ }^{4}$ Management Data Center, Rabin Medical Center, Petah Tiqwa, Israel
}

Received 7 February 2013; revised 9 March 2013; accepted 16 March 2013

Copyright (C) 2013 E. Stoupel et al. This is an open access article distributed under the Creative Commons Attribution License, which permits unrestricted use, distribution, and reproduction in any medium, provided the original work is properly cited.

\section{ABSTRACT}

The links of many medical-biological events with high levels of geomagnetic activity (GMA) are widely discussed. In recent years, several medical phenomena were described in inverse distribution by time with GMA. Also a concurrent to GMA and solar activity force-cosmic ray activity (CRA) and closely related high energy neutron and proton fluxes are studied as a forces dominating at low GMA and solar activity in relation to considered medical events. The aim of this study was to explore the distribution of some important medical events on days with "Zero" GMA levels, accompanied by high CRA (neutron activity). Medical event data of the Grand Baku region (more than $3 \mathrm{mln}$ inhabitants), Azerbaijan, with daily distribution on the time 1 Dec. 2002-31 Dec. 2007 was compared to daily GMA Kp indices in general (Kp $>0,1837$ days) and 34 days daily GMA indices $K p=0$. Daily CRA data was also compared using neutron monitoring data from two stations. Daily averaged data and their standard deviations on the mentioned GMA levels were compared and statistical significance was established. Results revealed a significant rise in the number of emergencies $(n=1,567,576)$ and total deaths number $(n=46,360)$ at the days of "Zero" GMA level. These days were accompanied by significant rise of CRA (neutron activity). For Sudden Cardiac Deaths (SCD, $n=1615$ ) and cerebral stroke (CVA, $n=10,054)$ the in- crease achieved strong trend to significance level. Acute Myocardial Infarction occurrence (morbidity) and trauma were also absolutely more registered at days with "Zero" GMA level, despite the small number of such days. The average Infection numbers show an inverse relationship with absolutely high registry at the "Zero" GMA level days. Study linking environmental physical activity levels and the human medical data shows that geomagnetic field variations accompanied by the increased level of cosmic ray activity, can have either direct or indirect adverse effects on human health and physiology, even when the magnitude of the geomagnetic field disturbance is extremely small or even is equal to zero. On days of "Zero" daily Kp indices describing Geomagnetic Activity, accompanied by high Cosmic Ray Activity (neutron activity), more medical emergencies and total death number (daily) occurred. Sudden Cardiac Deaths and Cerebral Stroke numbers show a strong trend to significant rise. Absolute increase of number of Acute Myocardial Infarction and less Infections, not achieving statistical significance, was also observed. These results are additional data for considering Cosmic Ray Activity (neutron activity) as an additional factor involved in time distribution of human medical events.

Keywords: Geomagnetic Activity; Solar Activity; Cosmic Ray Activity; Neutron Monitor; Morbidity; Mortality 


\section{INTRODUCTION}

The Earth is largely protected from the solar wind, a stream of energetic charged particles emanating from the Sun, by its magnetic field, which deflects most of the charged particles.

Earth's magnetic field (geomagnetic field) changes over time and extends from the Earth's inner core to where it meets the solar wind. The solar wind is responsible for the overall shape of Earth's magnetosphere, the sphere protecting the Earth, and fluctuations in its speed, density, direction, and entrained magnetic field strongly affect Earth's local space environment and technological, biological and ecological systems on the Earth [1-3].

In general, conditions on the Sun and in the solar wind, interplanetary space, the magnetosphere, ionosphere and thermosphere constitute the so called "Space Weather" [4]; they can influence not only the performance and reliability of space-borne and ground-based technological systems, but can also endanger many kinds of human activities, particularly in connection to human life itself and human health. For more details about the scientific aspects of space weather and its effects, readers are referred to Bothmer and Daglis [5] and Crosby et al. [6]. Impacts on space-borne and ground-based technologies are well highlighted in [7,8]. Review paper by Palmer et al. [9] and recent paper by Babayev et al. [10] summarize some of the major works performed in the field of heliobiology and solar-terrestrial relations over the last decades and describe potential effects of solar and geomagnetic variability on terrestrial biological systems.

Frequently, the Earth's magnetosphere is hit by solar flares and hot plasma eruptions/ejections from the Sun causing geomagnetic storms, provoking displays of aurorae. The short-term instability of the magnetic field is measured with the $\mathrm{K}$-index .The planetary $\mathrm{Kp}$ index is derived by calculating a weighted average of $\mathrm{K}$-indices from a network of geomagnetic observatories. The $\mathrm{K}$ index ranges from zero (no disturbance) to 9 in a maximum disturbance. The geomagnetic A-index provides a daily average level for geomagnetic activity and measures equivalent disturbance amplitude of a geomagnetic station ranging from 0 to 400 nano-Tesla (nT) when 0 indicates virtually no geomagnetic disturbance. Planetary Ap index is averaged planetary A-index based on data from a set of specific Kp stations. Table 1 presents the geomagnetic activity (GMA) levels and their gradation based on 3-hourly measurements of the GMA in the middle as well as high latitudes, where the level of GMA is usually strong [11].

Magnetosphere of the Earth also protects our planet from cosmic rays that would strip away the upper atmosphere, including the ozone layer that protects the Earth from harmful ultraviolet radiation. Cosmic ray activity (CRA) is related with highest level of known energy radiation (achieving levels of $10^{21-22} \mathrm{eV}$ and closely connected with high energy $(>90-100 \mathrm{MeV})$ space proton flux. CRA on the Earth's surface is usually measured by neutron activity (imp/min); these neutrons are remains of atoms crushed by cosmic rays. Behavioral extremes were related with daily levels of GMA and geomagnetic storms. Relevant studies in the XX-XXI c.c. considered the biologic actions of the GMA [12-15] and investigated such human-related functions like central nervous system (CNS), cardiovascular system components, immunity and different sorts of medical emergencies in cardiology, neurology and other disciplines of medicine [16-23]. Studies on CRA (neutron activity) were helpful in explaining last decades data about medical events concentrated on low (Quiet $\mathrm{I}^{0}$ ) GMA levels [21,24-27]. Such studies appeared in the fields of sudden cardiac death (SCD), life threatening cardiac arrhythmias, myocardial infarction occurrence and many other medical events.

Heliobiology is the branch of science that deals with the impact of solar activity and related effects on living organisms (sometimes the term "cosmobiology" is used; "heliomedicine" also appears in some papers and reports, and "clinical cosmobiology" was introduced as a new branch of biology by E.Stoupel in 1989 [28,29]).

More controversial is the question of whether the geomagnetic environment when disturbed can have either direct or indirect effects on human health and physiology, even when the magnitude of the disturbance is small or extremely small.

Table 1. Geomagnetic activity levels and their gradations.

\begin{tabular}{cccc} 
Geomagnetic activity category Geomagnetic activity “Ap" index range & Typical values of geomagnetic activity "Kp" index & Amplitude (nano-Tesla) \\
\hline 1. Quiet $\left(\mathrm{I}^{0}\right)$ & $0<\mathrm{Ap}<8$ & Usually $>3$ & $0-20$ \\
2. Unsettled $\left(\mathrm{II}^{0}\right)$ & $8<\mathrm{Ap}<16$ & Usually $>3$ & $21-40$ \\
3. Active $(\mathrm{III})$ & $16<\mathrm{Ap}<30$ & Few values of 4 & $41-70$ \\
4. Minor storm $\left(\mathrm{IV}^{0}\right)$ & $30<\mathrm{Ap}<50$ & Mostly 4 and 5 & $71-120$ \\
5. Major storm $\left(\mathrm{IV}^{0}\right)$ & $50<\mathrm{Ap}<100$ & Some indices 6 & $121-200$ \\
6. Severe storm $\left(\mathrm{IV}^{0}\right)$ & $100<\mathrm{Ap}$ & Some indices 7 & $201->550$ \\
\hline
\end{tabular}


Studies linking heliogeophysical activity level and the human physiological health state (see: reviews $[9,10]$ ) show that a subset of the population is predisposed to adverse health due to geomagnetic variations and extremely high as well as extremely low values of GMA seem to have adverse health effects.

In this paper we aimed to explore the distribution of some important medical events on days with "Zero" ("0") Kp GMA indices, accompanied by relatively high CRA. We used epidemiological data showing the temporal and spatial distribution of defined events or health disturbances involving considerable numbers of test subjects over several years (temporal distribution of emergency calls and hospital admissions, and so on).

\section{PATIENTS AND METHODS}

Environmental physical activity (solar activity, geomagnetic activity, cosmic ray activity) is one of the significant regulating forces in biology. The purpose of our collaborative and interdisciplinary study was checking possible links between daily different levels of GMA (with levels $\mathrm{I}^{0}-\mathrm{IV}^{0}$, for mid-latitudes) and CRA (neutron monitor data, imp/min on the Earth's surface), and medical events data. Time span covered by the data was chosen from 1 Dec. 2002 to 31 Dec. 2007 (continuous data).

Daily medical database was created according to WHO standards in 22 Emergency and First Medical Aid Stations (EFMAS) spread on big urban area (the Absheron Peninsula located at mid-latitudes $\left(40^{\circ} 23^{\prime} \mathrm{N}\right.$, $49^{\circ} 51^{\prime} \mathrm{E}$ ), including Baku capital city of Azerbaijan with more than 3 million of inhabitants) as well as in the Central Emergency and First Medical Aid Station in Baku. $1,567,576$ calls for emergency medical help were included in study, as well as 46350 deaths from all causes, 1615-sudden cardiac deaths (SCD), 1201-cardiac deaths, 7817-acute myocardial infarction, 10054-cerebral stroke (CVA) occurrence, 54854-trauma cases were investigated. 34 days with "Zero" GMA $(\mathrm{Kp}=0)$ were found in the study period and 1837 days with GMA index $\mathrm{Kp}>0$ were used for comparison.

Medical data was created and analyzed together with cosmophysical data for the considered time period. As we considered the period of relative economical and social stability in Azerbaijan (2002-2007), possible negative factors as a result of the occurrence of major socioeconomic changes in a newly independent country, in our opinion, did not influence so deeply the principal results of this study. Despite these changes, however, the solar and geomagnetic activity parameters were in effect all the time.

The following space weather (cosmophysical) parameters were used in our studies for the same time period:

For GMA: Kp and Ap geomagnetic indices;
For CRA: the neutron monitoring data on the Earth's surface.

Data for GMA were obtained from the US NOAA National Geophysical Data Center (www.ngdc.noaa.gov/) and NOAA Space Environment Center, Boulder, Colorado (www.sec.noaa.gov). CRA daily data was from the Moscow Cosmic Ray Station (Neutron Monitor), IZMIRAN, Russian Academy of Sciences

(http:/helios.izmiran.rssi.ru/cosray/main.htm), as well as the Oulu University, Finland (http://cosmicrays.oulu.fi/).

\section{STATISTICS}

Daily average's for the analyzed medical events at the days with "Zero" GMA levels and the standard deviations were compared. Statistical significance between the daily averages was established. Significance of $95 \%$ and higher was accepted as significant, these of $90 \%$ - 94\% as a strong trend to significance, meanwhile less than $90 \%$ - as a non-significant (N.S.).

\section{RESULTS}

Table 2 presents the comparative data of medical events on days with "Zero" GMA and higher activity level days. We can divide the results in a number of groups: 1) showing significant differences (high numbers of groups); 2) showing a strong trend for significant differences; 3) absolutely different, but not achieving significance; 4) minimally different.

High significant differences were revealed in the emergency calls $(p<0.0001)$ and total deaths daily data $(p=0.0076)$, both high on the days with "Zero" GMA. A strong trend for significant differences were seen for $\operatorname{SCD}(\mathrm{p}=0.077)$ and cerebral stroke (CVA) $(\mathrm{p}=0.10)$ in all these groups higher events number took place at zero GMA days, despite they small number. The groups with absolute difference, but not statistically significant were Acute Myocardial Infarction (AMI), trauma and infections. Infections were the only group that their occurrence was low at days with "Zero" GMA. The cardiac deaths (not sudden cardiac deaths) numbers were close to equal. At days of "Zero" GMA there was discovered significantly high CRA (neutron activity) $(\mathrm{p}<0.0001)$ for both neutron monitoring stations' data.

\section{DISCUSSION}

At the pick of a stream of studies investigating and confirming many medical phenomena rising on high GMA levels (arterial pressure, blood coagulation, CReactive protein (CRP), capillary circulation blood disturbances, deaths from some forms of stroke, link to seizures and severity of migraine attacks, changes in the natural history of acute eye diseases) [17,18,30], some additional studies presented inverse results. In these 
Table 2. Comparison of acute cardiovascular events with "Zero" Geomagnetic Activity (GMA) days and high Cosmic Ray Activity (CRA) (neutron activity), Baku, Azerbaijan, 2002-2007.

\begin{tabular}{|c|c|c|c|c|c|c|c|c|c|c|c|}
\hline & $\begin{array}{c}\text { All } \\
\text { emergencies }\end{array}$ & $\begin{array}{c}\text { All } \\
\text { deaths }\end{array}$ & AMI & $\begin{array}{l}\text { Stroke } \\
\text { (CVA) }\end{array}$ & Infections & Trauma & $\begin{array}{c}\text { Cardiac } \\
\text { deaths }\end{array}$ & SCD & $\begin{array}{c}\mathrm{MACE}^{*} \\
(\mathrm{AMI}+\mathrm{CVA}+\mathrm{SCD})\end{array}$ & $\begin{array}{c}\text { Oulu } \\
\text { station } \\
\text { neutrons }\end{array}$ & $\begin{array}{c}\text { Moscow } \\
\text { station } \\
\text { neutrons }\end{array}$ \\
\hline \multicolumn{12}{|c|}{ GMA Kp and Ap indices $=0$, middle latitudes } \\
\hline n (days) & 34 & 34 & 34 & 34 & 34 & 34 & 34 & 34 & 34 & 34 & 34 \\
\hline Sum & 32,354 & 960 & 153 & 212 & 324 & 1043 & 29 & 41 & 406 & & \\
\hline Avg & 951.6 & 28.2 & 4.5 & 6.2 & 9.5 & 30.7 & 1.4 & 1.9 & 11.9 & 6498.4 & 9356.3 \\
\hline StDev & 107.8 & 7.2 & 2.7 & 2.8 & 5.8 & 7.2 & 0.7 & 0.9 & 4.5 & 170.4 & 240 \\
\hline \multicolumn{12}{|c|}{ GMA Kp and Ap indices $>0$, middle latitudes } \\
\hline n (days) & 1823 & 1823 & 1823 & 1823 & 1823 & 1823 & 1823 & 1823 & 1823 & 1823 & 1823 \\
\hline Sum & $1,535,222$ & 45,400 & 7664 & 9842 & 18,514 & 53,811 & 1172 & 1574 & 19,080 & & \\
\hline Avg & 842.1 & 24.9 & 4.3 & 5.5 & 10.2 & 29.5 & 1.4 & 1.6 & 10.5 & 61159.4 & 8883.60 \\
\hline StDev & 160 & 6.3 & 2.1 & 2.5 & 4.9 & 9.3 & 0.7 & 0.9 & 3.7 & 334.0 & 518.2 \\
\hline p-values & $<0.0001$ & 0.0076 & ${ }^{* *}$ N.S. & 0.1 & ${ }^{* *}$ N.S. & ${ }^{* *}$ N.S. & ${ }^{* *}$ N.S. & 0.07 & 0.058 & $<0.0001$ & $<0.0001$ \\
\hline
\end{tabular}

*MACE-Major Acute Cardiovascular Events; ${ }^{* *}$ N.S.: Non-significant.

studies some medical events were significantly and inversely related with the level of GMA. Such results were seen for SCD in a number of studies [15,21,26,27], different forms of cardiac arrhythmia (some forms of them are predictors or components of SCD), also for atrial fibrillation (not only a significant cardiac lesion, but a major risk factor for stroke) [31-36]. In a number of following observations also significant links were seen for total number of AMI and its different subtypes (STEMI, NSTEMI, Q-wave and non-Q-wave AMI) [21,35]. Similar findings were published for great groups of cerebral stroke (CVA) [16]. Recent studies confirmed that more than $75 \%$ of AMI are a result of atheroma fissuring and/or rupture [37-39] and strong links connect timing of these events with high CRA (neutron activity).

Results of our present study revealed evidence that at days with high neutron activity (CRA) there were more medical emergencies and more deaths. Death in most cases is a result of fatal cardiac arrhythmia or heart standstill-asystolia. A strong trend of SCD (mostly result of fatal cardiac arrhythmia-ventricular tachycardia, fibrillation) occurred more often on days of high CRA (neutron activity) [25,26,34,35,40].

CVA-mostly result of ischemic stroke-cerebral infarction as result of thrombosis, and also atheroma rupture or embolism-closely connected with atrial fibrillation $[17,31,33]$ and forms of cardiac arrhythmia $[17,33]$ in the industrialized countries and hemorrhagic (bleedings) in the brain, mostly as result of uncontrolled hypertension, in the developing countries [41] have shown strong trends at high CRA.
An absolutely high number of AMI morbidity was also seen in our study, like in other large quoted studies $[19,21,25,40]$, but not achieving significance, as a result of only 34 "Zero" GMA days in this study. For most of these groups statistical significance of higher occurrence at "Zero" GMA days could be achieved by having such days number close to 99 - 100. The role of high CRA (neutron activity) and low GMA is worth of special attention, because most studied links with increased GMA and medical phenomena are registered at days of geomagnetic storms ( $\mathrm{IV}^{0}$ level of GMA)-relatively rare geophysical phenomena in the middle latitudes. For a long term we found geomagnetic storms in average at $3 \%-4 \%$ of days yearly, only sometimes achieving the $6.0 \%$ margin. In a recent couple of years (2007-2008) such level of GMA was not registered in the middle latitudes at all. Low (Quiet- $I^{0}$ ) GMA level days in most years in this part of the globe are accounting more than $35 \%$ (49.5\% for $1995-2006)$ of yearly days

(http://helios.izmiran.rssi.ru/cosray/ main.htm).

It is presumed that high neutron activity, accompanying the lowest GMA level can affect electrical heart instability, a basis for cardiac arrhythmia, and also, is an additional risk factor for unstable (result of disturbed lipid metabolism in the artery wall) atheroma ruptures and fissuring - a basis for the latest stage of the intravascular catastrophic-complete occlusion by thrombus in the region of atheroma plaque disruption and developing infarction in the blocked from oxygen and other life support supply in the zone of "culprit" artery location (heart muscle, brain). One of presumed ways of neutron 
activity action on the mentioned organ on cellular-molecular levels can be their addiction to $\mathrm{H}^{+}$ions, especially high distributed in lipid concentration places (unstable atheroma and similar locations), conversion neutrons (after joining the $\mathrm{H}^{+}$ion) to protons, that aggressively attacks cell nuclei and other cells parts and can act as one of factors for fatal consequences (SCD, myocardial ruptures in AMI, fatal arrhythmias in ischemic cardiomyopathies and repeated AMI) $[25,35,42-44]$.

In addition to the mentioned GMA effects on migraine attacks severity, seizures, observations of the inverse relationship to GMA and links to CRA (neutron activity) on timing of suicide were published [16,45]. Suicidal behavior is often connected with depression. At the same time artificial magnetic fields found their place in severe depression treatment $[46,47]$. Physical factors' involvement in central nervous system, eye and other human organs functions can be linked with timing of traffic accidents and trauma, as it was seen in previous studies, comparing four levels of GMA $[16,23,40]$, and in this study, concentrating on days with "Zero" GMA level. The presented data demonstrated the possible effects of high CRA (neutron activity) on a number of human pathologies, and mortality in general. In three studies of other groups with participation of authors, published recently, it was shown: 1) a significant rise of admissions for AMI on days following the days with "Zero" GMA levels, mostly on the first and second days at $23 \%$ and prolonged until the 6-th day after the "Zero" GMA level day $[48,49]$; 2) rising lesions in the Left Anterior Descending Coronary Artery (LAD)-the most serious lesion among the three coronary arteries-concomitant with drop of GMA level by $28 \%$ in $\mathrm{I}^{0}$ level GMA days compared to $\mathrm{IV}^{0}$ GMA days and achieving $62 \%$ rise at days of "Zero" GMA level [50].

Inverse correlation of GMA with CRA (neutron activity) ( $\mathrm{r}=-0.66, \mathrm{p}<0.0001)$ and CRA (neutron activity) with solar activity are similar $(\mathrm{r}=-0.85)$ [49-51]. The last relationship explains the much higher frequency of zero GMA on the lower part of the 11-year solar activity cycle.

Study limitations were relative small number of "Zero" GMA days and absence of data about events in days following the "Zero" GMA level. Accumulating similar observations on a greater number of "Zero" GMA level days would be an additional step forward.

\section{CONCLUSIONS}

Study linking environmental physical activity levels and the human medical data shows that human beings are predisposed to adverse health effects due to geomagnetic and cosmic ray activity variations and extremely high as well as extremely low values of GMA have health ef- fects.

Geomagnetic field variations accompanied by the increased level of cosmic ray activity, can have either direct or indirect adverse effects on human health and physiology, even when the magnitude of the geomagnetic field disturbance is extremely small or even is equal to zero.

On days of "Zero" daily Kp indices describing Geomagnetic Activity, accompanied by high Cosmic Ray Activity (neutron activity), more medical emergencies and total death number (daily) occurred. Sudden Cardiac Deaths and Cerebral Stroke numbers show a strong trend to significant rise. Absolute increase of number of Acute Myocardial Infarction and less Infections, not achieving statistical significance, was also observed.

These results are additional data for considering Cosmic Ray Activity (neutron activity) as an additional factor involved in time distribution of human medical events.

\section{REFERENCES}

[1] Phillips, K.J.H. (1995) Guide to the sun. Cambridge University Press, Cambridge, $400 \mathrm{p}$.

[2] Miroshnichenko, L.I. (2001) Solar cosmic rays. Astrophysics and Space Science Library, Springer, Berlin, 492 p.

[3] Wang, H. and Xu, R. (2002) Solar-terrestrial magnetic activity and space environment. COSPAR Colloquia Series, 14, 474.

[4] Song, P., Singer, H.J. and Siscoe, G.L. (2001) Space weather. American Geophysical Union's Geophysical Monograph Series, 125, 440.

[5] Bothmer, V. and Daglis, I.A. (2006) Space weather: Physics and effects. Environmental Sciences, Springer Praxi Books, Berlin, 476 p.

[6] Crosby, N.B., Rycroft, M.J. and Tulunay, Y. (2006) Surveys in Geophysics, 27, 319. doi:10.1007/s10712-005-6204-3

[7] Daglis, I.A. (2001) Space storms and space weather hazards. NATO Science Series, II. Mathematics, Physics and Chemistry, Kluwer Academic Publishers, Boston, 38.

[8] Koskinen, H., Tanskanen, E., Pirjola, R., et al. (2001) Space weather effects catalogue. ESA Space Weather Study (ESWS), ESTEC/Contract No. 14069/99/NL/SB.

[9] Palmer, S.J., Rycroft, M.J. and Cermack, M. (2006) Solar and geomagnetic activity, extremely low frequency magnetic and electric fields and human health at the earth's surface. Surveys in Geophysics, 27, 557. doi:10.1007/s10712-006-9010-7

[10] Babayev, E.S., Crosby, N.B., Obridko, V.N. and Rycroft, M.J. (2012) Potential effects of solar and geomagnetic variability on terrestrial biological systems. In: Georgeta, M. and Crisan, D., Eds., Advances in Solar and SolarTerrestrial Physics, Research Signpost, India, 329-376.

[11] NOAA-USAF (1988) SESC glossary of solar-terrestrial terms. Boulder, Co., USA, 1-69. 
[12] Barnothy, M.F. (1969) Biological effects of magnetic fields. Plenum Press, New York.

[13] Dubrov, A.P. (1978) The geomagnetic field and lifeMagnetobiology. Plenum Press, New York.

[14] Ganelina, I.E. (1969) Sudden deaths in acute myocardial infarction and problems of reanimation. Clinical Medicine, 11, 111-119.

[15] Knox, E.G., Armstrong, E. and Lancashire, R. (1979) Heart attacks and geomagnetic activity. Nature, 281, 646648. doi:10.1038/281564a0

[16] Stoupel, E., Kalediene, R., Petrauskiene, J., Starkuviene, S., Abramson, E., Israelevich, P. and Sulkes, J. (2011) Twenty years study of solar, geomagnetic, cosmic ray activity links with monthly deaths number (n-850304). Journal of Biomedical Science \& Engineering, 4, 1-9.

[17] Stoupel, E. (2002) The effect of geomagnetic activity on cardio-vascular parameters. Biomedicine \& Pharmacotherapy, 56, 247-256. doi:10.1016/S0753-3322(02)00299-8

[18] Stoupel, E., Wittenberg, C., Zabludovski, J. and Boner, G. (1995) Ambulatory blood pressure monitoring in patients with hypertension on days of high and low geomagnetic activity. Journal of Human Hypertension, 9, 293-294.

[19] Stoupel, E. (1976) Forecasting in cardiology. John Wiley \& Sons, New York, 1-141.

[20] Stoupel, E., Babayev, E., Mustafa, F., Abramson, E., Israelevich, P. and Sulkes, J. (2007) Acute myocardial infarction occurrence: Environmental links-Baku 20032005 data. Medical Science Monitor, 13, BR175-BR179.

[21] Stoupel, E., Keret, R., Assa, S., Kaufman, H., Shimshoni, M. and Laron, Z. (1983) Secretion of growth hormone, prolactin and corticosteroids during different levels of geomagnetic activity. Neuroendocrinology Letters, 6, 365368.

[22] Stoupel, E., Joshua, H. and Lahav, J. (1996) Human blood coagulation parameters and geomagnetic activity. European Journal of Internal Medicine, 7, 217-220.

[23] Stoupel, E., Zhemaityte, D., Drungeliene, D., Martinkenas, A., Abramson, E., et al. (2002) Klaipeda cardiovascular emergency aid services correlate with 10 cosmophysical parameters by time of occurrence. Journal of Clinical and Basic Cardiology, 225-227.

[24] Stoupel, E., Domarkiene, S., Radishauskas, R., Abramson, E., Israelevich, P. and Sulkes, J. (2006) Neutrons and sudden cardiac death (SCD) codes 121-125 ICD 10. Journal of Basic and Clinical Physiology and Pharmacology, 17, 45-53. doi:10.1515/JBCPP.2006.17.1.45

[25] Stoupel, E., Israelevich, P., Petrauskiene, J., Kalediene, R., Abramson, E., Gabbay, U., et al. (2002) Cosmic rays activity and monthly number of deaths: A correlative study. Journal of Basic and Clinical Physiology and Pharmacology, 13, 23-32. doi:10.1515/JBCPP.2002.13.1.23

[26] Stoupel, E., Abramson, E., Domarkiene, S., Shimshoni, M. and Sulkes, J. (1997) Space proton flux and the temporal distribution of cardiovascular deaths and suicide. International Journal of Biometeorology, 40, 113-116.

[27] Stoupel, E., Israelevich, P., Gabbay, U., Abramson, E., Petrauskiene, J., Kalediene, B., et al. (2000) Correlation of two levels of space proton flux with monthly distribution of deaths from cardiovascular disease and suicide. Journal of Basic and Clinical Physiology and Pharmacology, 11, 63-71. doi:10.1515/JBCPP.2000.11.1.63

[28] Stoupel, E. (1989) Clinical cosmobiology. Canadian Medical Meteorology Network, Bio-Electro-Magnetics Institute, 1.

[29] Stoupel, E., Shimshoni, M., Keret, R., et al. (1990) Solarterrestrial predictions. Proceedings of workshop at Leura, Australia, 16-20 October 1989, US air force geophysics laboratory, Bedford, Mass, USA. IPS Radio and Space Services, Chatswood, NSW-2057, Australia. Department of Commerce, National Oceanic Atmospheric Administration, Boulder, Co., USA, 152.

[30] Stoupel E, Domarkiene S, Radishauskas R, Abramson E, Sulkes J. Deaths from ischemic and hemorrhagic stroke on days of different levels of geomagnetic activity. Seminars Cardiol. 2003; 9(2):46-51.

[31] Stoupel, E. (2006) Cardiac arrhythmia and geomagnetic activity. Indian Pacing and Electrophysiology Journal, 6 , 49-53.

[32] Stoupel, E., Domarkiene, S., Radishauskas, R. and Abramson, E. (2002) Sudden cardiac death and geomagnetic activity: Links to age, gender and agony time. Journal of Basic and Clinical Physiology and Pharmacology, 13, 11-21. doi:10.1515/JBCPP.2002.13.1.11

[33] Stoupel, E., Babayev, E.S., Mustafa, F.R., Abramson, E., Israelevich, P. and Sulkes, J. (2006) Clinical cosmobiology-Sudden cardiac death and daily/monthly geomagnetic, cosmic ray and solar activity-The Baku Study (2003-2005). Sun and Geosphere, 1, 13-16.

[34] Stoupel, E., Kusniec, J., Mazur, A., Abramson, E., Israelevich, P. and Strasberg, B. (2008) Timing of life-threatening arrhythmias detected by implantable cardioverterdefibrillators in relation to changes in cosmophysical activity. Cardiology Journal, 15, 1-5.

[35] Stoupel, E., Domarkiene, S., Radishauskas, R., Bernotiene, G., Abramson, E., Israelevich, P., et al. (2004) Link between monthly rates of four subtypes of acute myocardial infarction and their corresponding cosmophysical activity parameters. Journal of Basic and Clinical Physiology and Pharmacology, 15, 175-184. doi:10.1515/JBCPP.2004.15.3-4.175

[36] Stoupel, E., Abramson, E., Israelevich, P., Sulkes, J. and Harell, D. (2007) Dynamics of serum C-reactive protein (CRP) level and cosmophysical activity. European Journal of Internal Medicine, 18, 124-128. doi:10.1016/j.ejim.2006.09.010

[37] Rittersma, S.Z., van der Wal, A.C., Koch, K.T., Piek, J.J., Henriques, J.P., Mulder, K.J., et al. (2005) Plaque instability frequently occurs days or weeks before occlusive coronary thrombosis. A pathological thrombectomy study in primary percutaneous coronary intervention. Circulation, 111, 1160-1165. doi:10.1161/01.CIR.0000157141.00778.AC

[38] Solem, J., Levin, M., Karlsson, T., Grip, L., Albertsson, P. and Wiklund, O. (2006) Composition of coronary plaques obtained by directional atherectomy in stable angina: Its relation to serum lipids and statin treatment. Journal of 
Internal Medicine, 259, 267-275. doi:10.1111/j.1365-2796.2006.01608.x

[39] Stoupel, E., Kalediene, R., Petrauskiene, J., Domarkiene, S., Radishauskas, R., Abramson, E., et al. (2004) Three kinds of cosmophysical activity: Links to temporal distribution of deaths and occurrence of acute myocardial infarction. Medical Science Monitor, 10, CR80-CR84.

[40] Wallaschofski, H., Lohmann, T., Hild, E., Kobsar, A., Siegemund, A., Spilcke-Liss, E., et al. (2006) Enhanced platelet activation by prolactin in patients with ischemic stroke. Journal of Thrombosis and Haemostasis, 96, 3844.

[41] Stoupel, E. (1980) Solar terrestrial predictions: Aspects for preventive medicine. In: Donnelly, R.F., Ed., Solarterrestrial predictions proceedings. NOAA Space Environment Laboratory, Silver Spring, G-29-G-40.

[42] Nias, A.H.W. (1998) An introduction to radiobiology. John Wiley \& Sons Ltd., New York.

[43] Stoupel, E., Assali, A., Teplitzky, I., Israelevich, P., Abramson, E. and Sulkes, J. (2008) The culprit artery in acute myocardial infarction in different environmental physical activity. International Journal of Cardiology, 126, 288290.

[44] Stoupel, E., Kalediene, R., Petrauskiene, J., Starkuviene, S., Abramson, E., Israelevich, P. and Sulkes, J. (2005) Suicide-homicide temporal interrelationship, links with other fatalities, and environmental physical activity. The Journal of Crisis Intervention and Suicide Prevention, 26, 85-89. doi:10.1027/0227-5910.26.2.85

[45] Grisaru, M.J., Abarbanel, R. and Belmaker, H. (1995) Slow 3 magnetic stimulation of motor cortexand frontal lobe in depression and schizophrenia. Acta Neuropsychiatrica, 7, 521-523.
[46] Rohan, M., Parow, A., Stoll, A.L., Demopulos, L., Friedman, S. and Dager, S. (2004) Low-field magnetic stimulation in bipolar depression using an MRI-based stimulator. The American Journal of Psychiatry, 161, 93-98. doi:10.1176/appi.ajp.161.1.93

[47] Stoupel, E., Babayev, E.S., Shustarev, P.N., Abramson, E., Israelevich, P. and Sulkes, J. (2009) Traffic accidents and environmental physical activity. International Journal of Biometeorology, 53, 523-534. doi:10.1007/s00484-009-0240-5

[48] Stoupel, E., Tamoshiunas, A., Radishauskas, R., Benotiene, G., Abramson, E. and Israelevich, P. (2011) Neutrons and the plaque: AMI (n-8920) at days of zero GMA/ high neutron activity (n-36) and the following days and week. Kaunas, Lithuania, 2000-2007. Journal of Clinical \& Experimental Cardiology, 12, 121-125.

[49] Stoupel, E, Assali, A., Teplitzky, I., Israelevich, E.P., Abramson, E., Sulkes, J. and Kornowski, R. (2008) The culprit artery in acute myocardial infarction in different environmental physical activity levels. International Journal of Cardiology, 126, 128-190. doi:10.1016/j.ijcard.2007.05.050

[50] Stoupel, E., Abramson, E. and Israelevich, P. (2011) Left anterior descending/right coronary arteries as culprit arteries in acute myocardial infarction $(n=2011)$ in changing physical environment, percutaneous coronary intervention data 2000-2011. Journal of Basic and Clinical Physiology and Pharmacology, 22, 91-96. doi:10.1515/JBCPP.2011.024

[51] Stoupel, E. (2012) Space weather and timing of cardiovascular events (clinical cosmobiology). Lambert Academic Publishing, $72 \mathrm{p}$. 